\title{
PLANO PAISAGÍSTICO PARA O MUNICÍPIO DE CUBATÃO, SP, BRASIL
}

\author{
LANDSCAPE PLAN FOR THE TOWN OF CUBATÃO, SP, BRAZIL
}

\section{AFONSO, Cintia Maria}

Arquiteta, mestre em ciência ambiental e doutora em paisagismo, é professora titular de paisagismo e estudos socioambientais em cursos de arquitetura e urbanismo de São Paulo.

E-mail: cintiafo@osite.com.br

\section{RESUMO}

O trabalho apresentado propõe um plano paisagístico para o município de Cubatão, situado na zona costeira do Estado de São Paulo, Brasil.

Para tanto, parte-se da identificação das características naturais e sócio-econômicas do município e da compreensão dos processos sociais e naturais definidores da configuração atual. Esse conjunto constitui a base analítica para a identificação dos principais problemas ambientais e paisagísticos do município.

São então formuladas diretrizes gerais de intervenção e diretrizes específicas para reordenamento da paisagem, com proposições de reorganização das redes de circulação, redistribuição de equipamentos sociais e serviços, proteção dos ecossistemas costeiros ainda conservados e recuperação dos ecossistemas degradados.

\section{Palavras-chave: Planejamento da paisagem, planejamento ambiental, zona costeira.}

\begin{abstract}
This study proposes a landscape plan for the town of Cubatão, which is situated on the coastal zone of São Paulo State, in Brazil.

Both socioeconomic and natural conditions, taken as dinamic processes of this coastal region, form the base information for planning. The identified environmental and landscape conditions, with its problems and conflicts, leed to the development of main goals and guidelines. The final step is the development of a landscape plan which aim to transform the circulation system, re-distribute social services according to the needs of different social groups, and protect coastal ecosystems, either by conservation or by restoring of degraded areas.
\end{abstract}

Key words: Landscape planning, environmental planning, coastal zone.

\section{Introdução}

Cada vez mais, cresce a consciência de que os problemas ambientais com os quais nos deparamos em nosso dia-a-dia não são casos isolados, mas que apresentam freqüência alarmante.

Nas cidades, vários desses problemas são conseqüência de modos de ocupação inadequados às condições locais, gerando enchentes, comprometendo condições de ventilação ou intensificando processos erosivos e de escorregamento de encostas.

Cabe aos arquitetos e urbanistas refletir e formular proposições para as várias questões a enfrentar, tanto como estudiosos dos processos urbanos quanto como profissionais capacitados a planejar e projetar o espaço urbano.

O trabalho apresentado a seguir está inserido nesse conjunto de preocupações e pretende analisar as condições ambientais e paisagísticas de um dos mais problemáticos municípios paulistas, o município de Cubatão. Foi desenvolvido como parte das atividades de ensino em arquitetura e urbanismo, na seqüência de disciplinas denominada "Projeto urbano e paisagismo"1. 
Na proposta de estudo foram incluídos: a) levantamento do processo histórico de ocupação e das características naturais e socioeconômicas do município; b) levantamento e análise gráfica da distribuição das atividades e redes de circulação, abastecimento, saneamento e comunicação; c) análise integrada dos dados estatísticos relativos ao município; d) formulação de objetivos e diretrizes gerais de intervenção; e) organização de um plano paisagístico geral, posteriormente detalhado para o setor oeste do município e para um de seus bairros carentes, o bairro cota 200.

\section{Fundamentos conceituais e metodológicos}

A proposta do plano paisagístico está fundamentada no entendimento do ambiente como conjunto de relações naturais e sociais e da paisagem como expressão material dessas relações.

Os sistemas natural e social não são estáticos, mas dinâmicos. Processos sociais como movimentos migratórios e crescimento populacional, como os processos de industrialização de algumas regiões ou desindustrialização de outras, ou como o desenvolvimento de novas tecnologias e produtos, motivam uma constante transformação das necessidades. Novas áreas para moradia, expansão do comércio ou construção de novas ferrovias, rodovias ou portos, modificam a paisagem.

Também variações naturais tais como alterações de temperatura ou precipitação, por exemplo, alteram o funcionamento do sistema natural e mudam regime dos rios ou condições de alimentação para espécies vegetais e animais, modificando também a paisagem.

Os fundamentos teóricos para as colocações acima foram estabelecidos por diversos autores. Para Antonio Carlos Robert Moraes, numa abordagem própria para estudos ambientais, os atributos geológico, climatológico, socioeconômico devem ser, desde o início investigados em seus aspectos de inter-relação e não apenas nas suas características intrínsecas e estanques, isto é, como fator dinâmico para a identificação dos níveis de vulnerabilidade e sustentabilidade de um determinado território. Os estudos para o planejamento ambiental só possuirão significado relevante se forem capazes de expressar, ao mesmo tempo e explicitamente, a dinâmica das configurações físico-naturais em interação contraditória com a dinâmica social em cada lugar e em todo o conjunto enfocado².

As inter-relações indicadas materializam-se na paisagem. Para Milton Santos, "a paisagem é diferente do espaço. A primeira é a materialização de um instante da sociedade. ... O espaço contém o movimento; é igual à paisagem mais a vida nela existente; é a sociedade encaixada na paisagem, a vida que palpita conjuntamente com a materialidade." 3 Ou, como coloca Silvio Soares Macedo, "... adota-se a idéia de paisagem como a expressão morfológica das diferentes formas de ocupação e, portanto, de transformação do ambiente em um determinado tempo."4

Essas afirmações conduzem necessariamente à análise das condições específicas de cada local para entendimento de suas características paisagísticas e dos processos naturais e sociais formadores e transformadores da paisagem sobre a qual se pretende intervir.

Assim, a identificação das características paisagísticas, bem como o entendimento do funcionamento dos sistemas natural e social e das relações estabelecidas nesse processo, forma a base analítica para a elaboração de proposições que visem modificar intencionalmente um lugar.

No estudo de caso proposto, os trabalhos tiveram início com o entendimento do processo histórico de ocupação do município de Cubatão e com a identificação de suas características naturais e sócio-econômicas. Assim, foi possível identificar os principais problemas do município passíveis de equacionamento por meio de um plano paisagístico.

O plano constituiu-se, então, da definição de estruturas e princípios de organização espacial, incluindo reorganização das redes de transporte, definição dos espaços livres urbanos, localiza- 
ção dos equipamentos públicos educacionais, de saúde e lazer, e definição dos remanescentes naturais que devem ser protegidos.

\section{Município de Cubatão: processos de ocupação e de transformação da paisagem}

O município de Cubatão está situado na porção central da zona costeira do Estado de São Paulo, no interior do estuário de Santos - São Vicente.

Ali são encontradas três formações vegetais, associadas às condições geológicas e geomorfológicas: mata atlântica sobre as encostas da Serra do Mar, vegetação de restinga sobre a estreita planície costeira, e manguezais, intimamente ligados aos processos estuarinos já que sua sobrevivência depende do fluxo das marés.

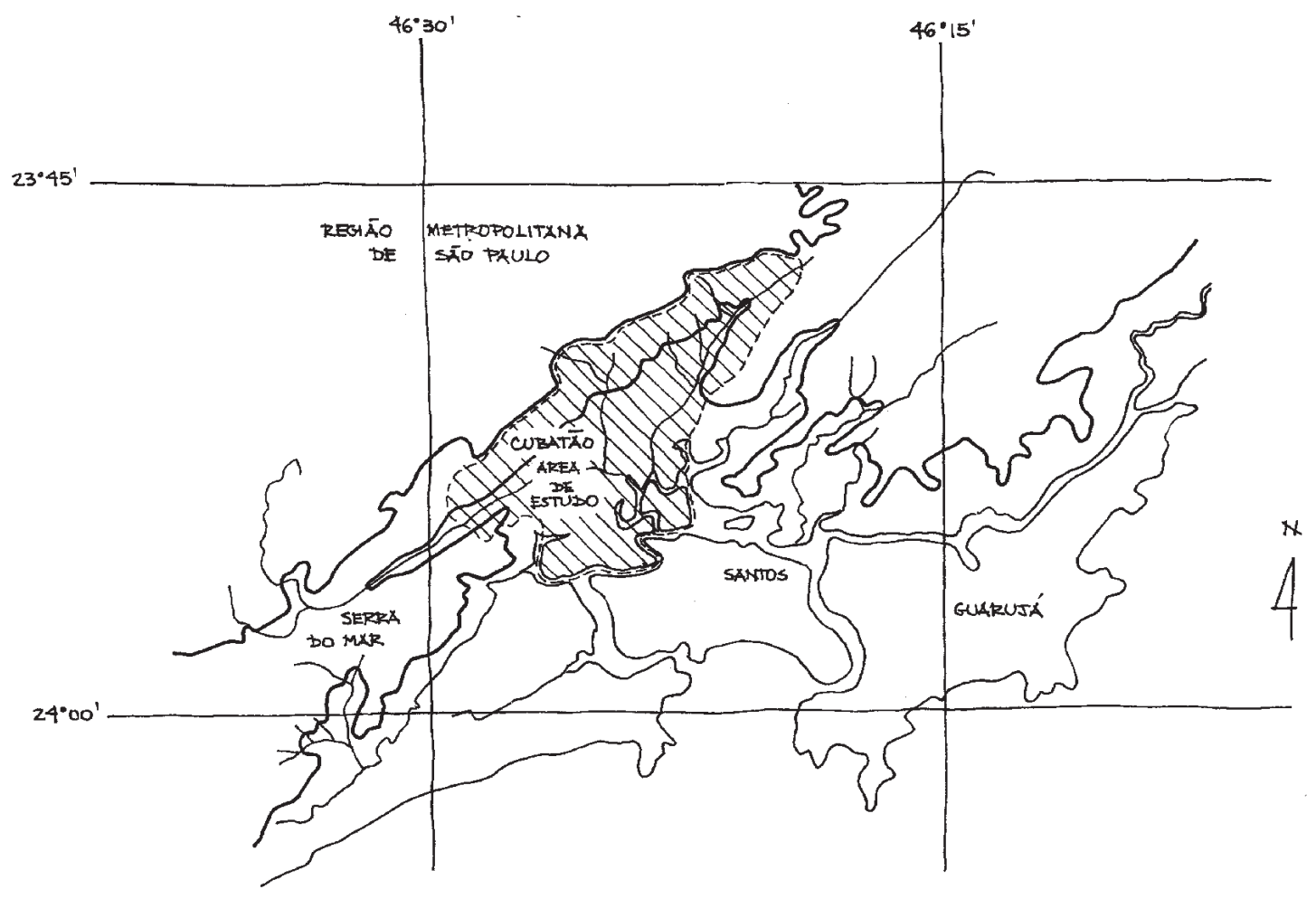

Localização do município de Cubatão

Cubatão teve sua origem como pouso das tropas que faziam o transporte de mercadorias e pessoas entre o porto de Santos e o planalto paulista. Os vários caminhos indígenas existentes foram sendo utilizados desde o início da colonização portuguesa até que se construiu a primeira via pavimentada para a transposição da Serra do Mar, a Calçada do Lorena. No século XX, a esse caminho pavimentado acresceram-se o Caminho do Mar e as rodovias Anchieta e Imigrantes.

O cruzamento das rodovias que demandam os setores norte e sul do litoral, com as várias rodovias que levam ao planalto, bem como sua posição privilegiada entre a Grande São Paulo (mercado consumidor) e o porto de Santos (recebimento de matérias-primas e transporte de produtos) foi o motivo principal da escolha intencional do município de Cubatão como sede do parque industrial petrolífero, petroquímico e siderúrgico de porte nacional ali implantado a partir da década de 1950. Essa importante atividade econômica motivou processos migratórios intensos, na busca por emprego nas indústrias que ali se instalavam. 
A escolha locacional do parque industrial, correta do ponto de vista econômico e de oferta de infra-estrutura, logo se mostrou complicada quanto às conseqüências das atividades industriais sobre o sistema natural. $\bigcirc$ padrão de circulação das águas no estuário dificulta a dispersão dos efluentes industriais lançados nos rios e os polventes permanecem no sistema alterando a qualidade das águas e dos manguezais.

Também os gases tóxicos resultantes dos processos industriais têm difícil dispersão devido à proximidade da Serra do Mar, que constitui importante barreira natural e estabelece condições limitadas de ventilação.

Assim, a partir da década de 1980, começaram a surgir em Cubatão importantes problemas relacionados com a polvição, amplamente noticiados nos meios de comunicação. A localização do parque industrial nos escassos terrenos favoráveis à ocupação e as más condições de distribuição de renda, também foram indutores da invasão de áreas legalmente protegidas, como o Parque Estadual da Serra do Mar e parte dos manguezais existentes no município.

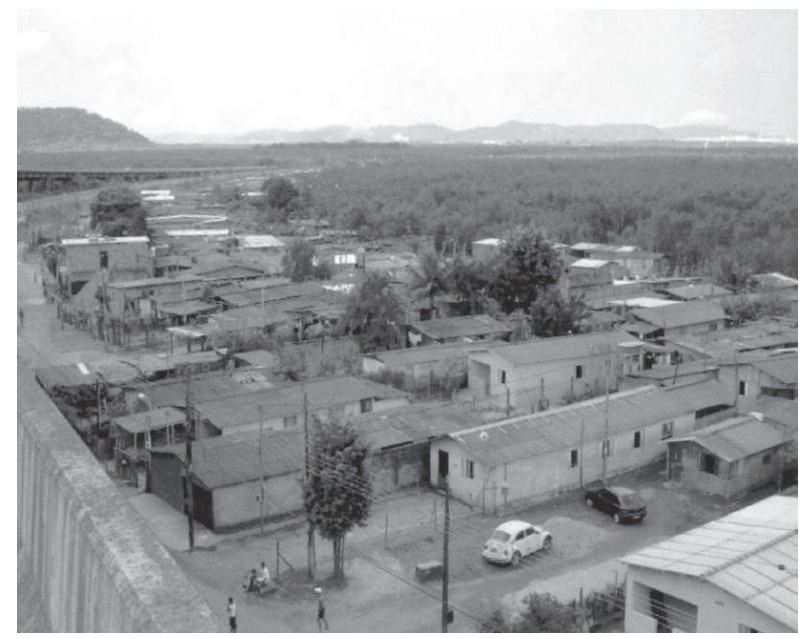

Manguezal de Cubatão invadido, aterrado e ocupado para construção de moradias

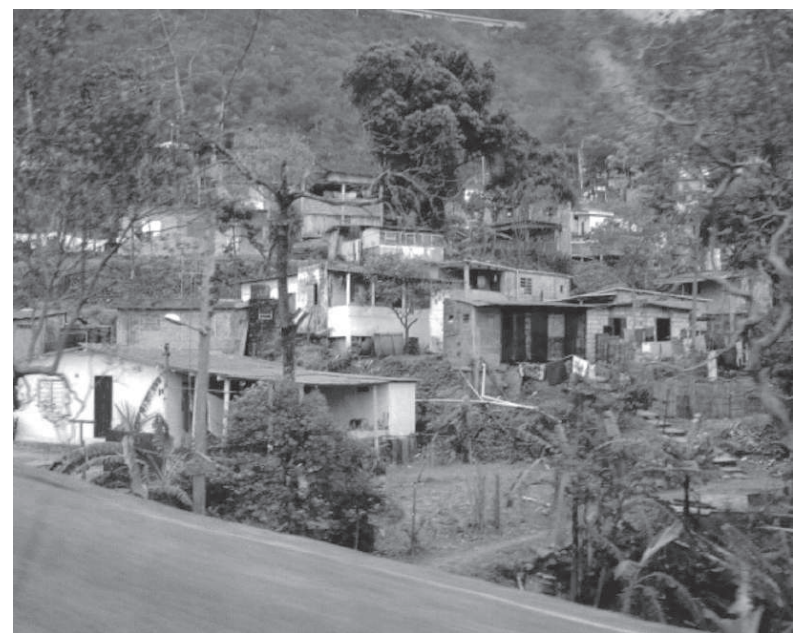

Área invadida situada dentro do Parque Estadual da Serra do Mar, conhecida como Bairro cota 200

Essas áreas invadidas expandem-se continuamente, sem implantação de redes de infra-estrutura e com moradias precárias. A política habitacional praticada tem tido resultados pontuais, principalmente voltados à solução de problemas mais candentes como a remoção das Vilas Socó (área invadida ao longo do oleoduto da Petrobrás e incendiada em 1984) e Parisi (originalmente situada junto do parque industrial e, portanto, muito próxima das fontes de polvição, foi transferida para outro local devido aos sérios problemas de saúde de seus moradores).

\section{Objetivos e diretrizes gerais de intervenção}

Existem em Cubatão duas classes de problema: a) degradação do sistema natural por polvição e por desmatamento para ocupação urbana; e b) carências sociais como déficit habitacional, altos índices de desemprego e baixos níveis de rendimento econômico da população. No ano de 2000, a renda média domiciliar per capita ${ }^{5}$ dos moradores do município era de apenas 1,77 salários mínimos. No mesmo ano, os domicílios com renda per capita de até $1 / 4$ de salários mínimos representavam $8,19 \%$ do total e de até $1 / 2$ salários mínimos, 15,2\%.

12 Essa constatação levou à proposição de dois principais objetivos de planejamento: a) controle, redução e eliminação da polvição do ar, das águas e do solo; e b) minimização dos problemas sociais.

A partir desses objetivos, foram estabelecidas as seguintes diretrizes gerais: 
- Criação de um fundo financeiro para recuperação ambiental e paisagística, constituído por parte dos lucros industriais (o município de Cubatão tem um altíssimo PIB per capita ${ }^{6}$, correspondente a R\$ 61.762,21 no ano de 2003). Essas despesas poderão ser revertidas em benefícios para as empresas participantes, já que podem ser qualificadas como ações de responsabilidade social e ambiental.

- Equacionamento dos problemas relativos à polvição do ar, das águas e do solo, com implantação de sistemas de tratamento de efluentes e gases em todas as indústrias; extensão da coleta de resíduos sólidos e da rede coletora de esgotos a toda população; construção de estações de tratamento dos esgotos urbanos; implantação de sistema de reciclagem dos resíduos urbanos e industriais passíveis de reaproveitamento; disposição correta dos resíduos sólidos urbanos e industriais não reaproveitáveis.

- Redução das carências sociais com a construção de escolas profissionalizantes para trabalhadores sem qualificação ou desempregados; distribuição eqüitativa de serviços e equipamentos sociais (transporte coletivo, postos de saúde, escolas e creches, equipamentos para lazer e espaços de convivência) nos diversos bairros e, principalmente, nas áreas irregularmente ocupadas.

- Implantação de um programa habitacional consistente e controle das áreas invadidas de modo a evitar sua expansão.

- Estabelecimento de condições especiais para construção de novas indústrias ou ampliação das existentes, como a participação no fundo financeiro de recuperação, implantação de programas efetivos de controle de polvição, além da absorção da mão-de-obra local ociosa.

\section{O plano}

A partir das diretrizes gerais, foram definidas as seguintes diretrizes para reordenamento das áreas urbanas e para proteção dos ecossistemas ainda conservados ou merecedores de recuperação:

- Reorganização e interligação da malha viária intra-urbana;

- Isolamento da malha rodoviária em relação ao trânsito intra-urbano;

- Oferta de equipamentos sociais e serviços públicos nas áreas irregulares já existentes;

- Delimitação de áreas de expansão urbana para uso residencial, principalmente voltadas a programas habitacionais populares;

- Proteção efetiva da Serra do Mar e manguezais, por meio de acordos, conscientização e fiscalização intensiva;

- Relocação de parte dos habitantes que ocupam irregularmente áreas legalmente protegidas.

Essas diretrizes foram espacializadas em diferentes escalas, indicando-se inicialmente os princípios gerais estabelecidos para todo o território municipal, de modo a permitir uma visão geral da proposta. Esses princípios foram posteriormente desenvolvidos para o setor oeste do município, aonde se concentraram as principais propostas de reorganização da paisagem.

Finalmente, foi elaborada uma proposta de reorganização paisagística para o bairro cota 200, área invadida localizada nas encostas serranas situadas dentro dos limites do Parque Estadual da Serra do Mar, importante unidade de conservação estadual. $O$ plano integra-se às propostas gerais de ordenamento do sistema viário, de recuperação da mata atlântica, de oferecimento de infra-estrutura e equipamentos sociais para os habitantes locais. 

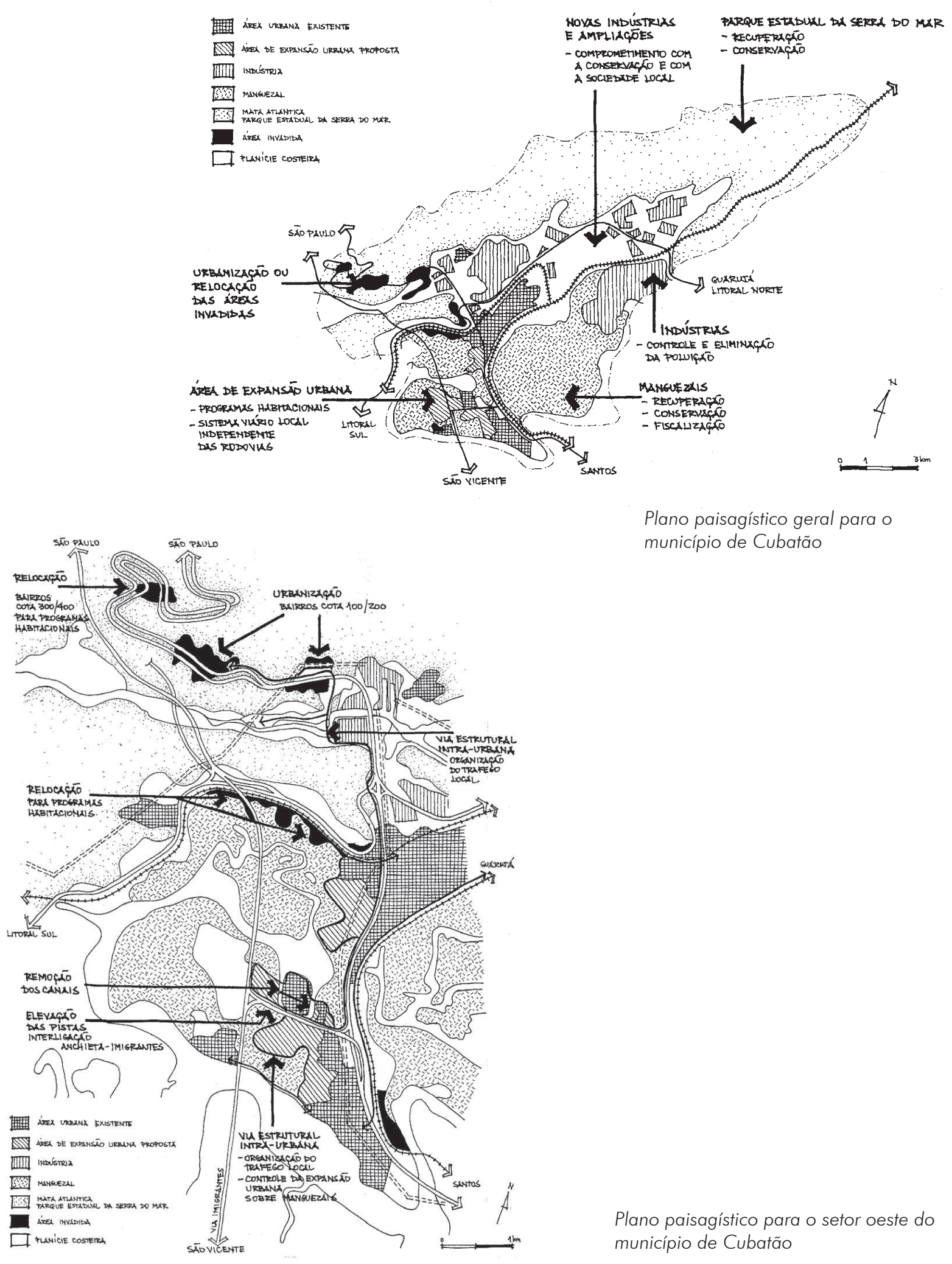

Plano paisagístico geral para o município de Cubatão

Plano paisagístico para o setor oeste do município de Cubatão 


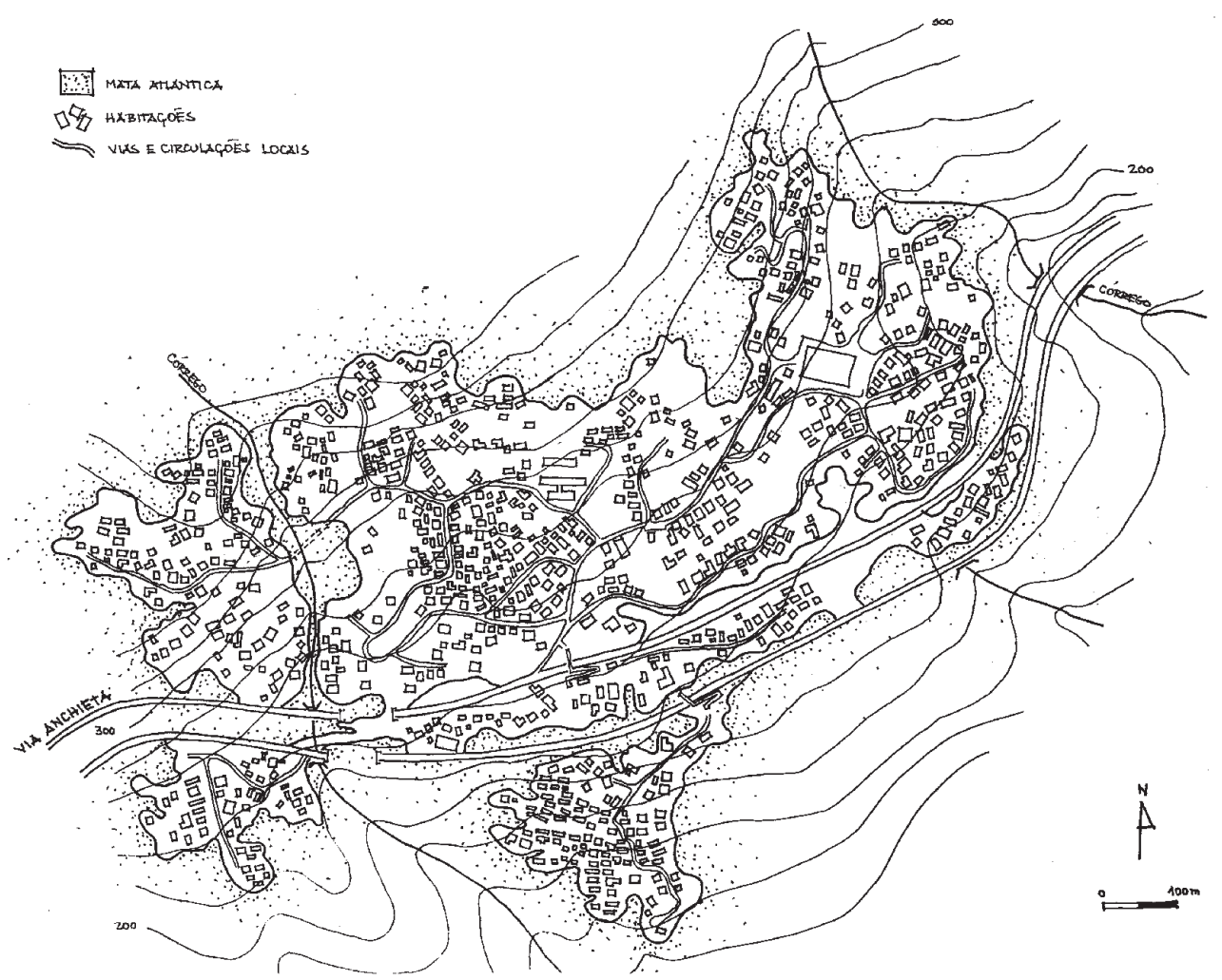

Configuração atual do bairro cota 200

SS HABHAGOES

EQUIPAMENTOS RECREXTIVOS

COMÉRCIO LOCALLE POSTO DE SXÚDE

- CRECHE

E TRTINAL PXRA ONIBUS URBNHOS

IIII REMOCAD̃ DXS HXBTHAOES

Ä. ÁREA PUSSIVEL DE LDENSXMENTO

口 ESTAPADO DE TRATRMENTO DE ESGOTOS

+ abustecimento

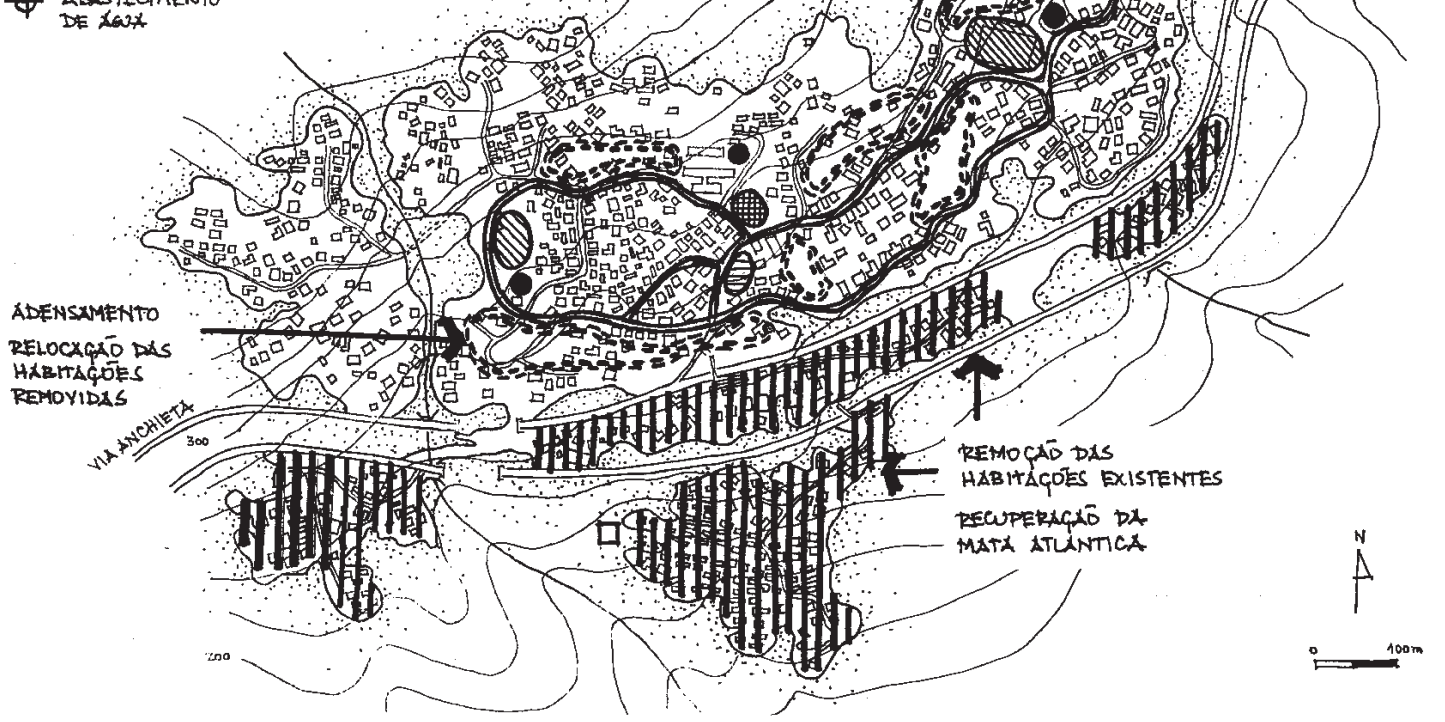

Proposta de reorganização da paisagem para o bairro cota 200 


\section{Notas}

(1) $O$ trabalho apresentado constituiu parte das atividades propostas e desenvolvidas durante o ano de 2005 nas disciplinas "Projeto urbano e paisagismo III-IV", do curso de Arquitetura e Urbanismo da Universidade Ibirapuera.

(2) MORAES, Antonio Carlos Robert. Configuração de metodologia para o macrozoneamento costeiro do Brasil: relatório final. Brasília, Ibama, 1993. p.11-12.

(3) SANTOS, Milton. Metamorfoses do espaço habitado. São Paulo, Hucitec, 1994. p.72-73.

(4) MACEDO, Silvio Soares. Paisagem, urbanização e litoral: do éden à cidade. São Paulo, 1993. p. 11.

(5) A fundação Seade define "Renda domiciliar per capita" como a soma das rendas das pessoas residentes nos domicílios, dividida pelo total dessas pessoas.

(6) A fundação Seade define "Produto interno bruto - PIB - per capita" como o total dos bens e serviços produzidos pelas unidades produtoras, ou seja, a soma dos valores adicionados acrescida dos impostos, dividida pela população da respectiva agregação geográfica.

\section{Bibliografia}

AFONSO, Cintia Maria. A paisagem da Baixada Santista: urbanização, transformação e conservação. 2002. Tese (Doutorado) - Faculdade de Arquitetura e Urbanismo, Universidade de São Paulo, São Paulo, 2002.

CUBATÃO, Prefeitura Municipal; UNIVERSIDADE DE SÃO PAULO. Faculdade de Arquitetura e Urbanismo da Universidade de São Paulo. Fupam. Plano Diretor de Desenvolvimento do Município de Cubatão. São Paulo: Fupam, 1995.

CUBATÃO, Prefeitura Municipal. Lei Complementar n. 2.512, de 10 de setembro de 1998 (institui o novo plano diretor do município de Cubatão). A Tribuna, Santos, p. 2, 14 set. 1998.

Lei Complementar n. 2.513, de 10 de setembro de 1998 (institui normas sobre o parcelamento, uso e ocupação do solo do município de Cubatão). A Tribuna, Santos, p. 2-13, 14 set. 1998.

FUNDAÇÃO SEADE. Perfil Municipal. Disponível em: <http://www. seade.gov.br>. Acesso em: 12 abr. 2005.

GOLDENSTEIN, Léa. Cubatão e sua área industrial. In: AZEVEDO, Aroldo de (Org.). Baixada Santista: Aspectos geográficos. São Paulo: Edusp, 1965, vol. 4, p. 11-65.

A industrialização da Baixada Santista: Estudo de um centro industrial satélite. 1972. Tese (Doutorado) Instituto de Geografia, Universidade de São Paulo, São Paulo, 1972.

GOOGLE EARTH. Foto aérea do bairro cota 200. Acesso em: 27 set. 2005.

GUTBERLET, Jutta. Cubatão: Desenvolvimento, exclusão social e degradação ambiental. São Paulo: Edusp - Fapesp, 1996.

MACEDO, Silvio Soares. Paisagem, urbanização e litoral: do éden à cidade. 1993. Tese (Livre-docência) - Faculdade de Arquitetura e Urbanismo, Universidade de São Paulo, São Paulo, 1993.

MORAES, Antonio Carlos Robert. Configuração de metodologia para o macrozoneamento costeiro do Brasil: relatório final. Brasília: Ibama, 1993.

POMPÉlA, Sérgio Luís et al. A degradação dos ecossistemas costeiros: Estudo de caso da Baixada Santista, São Paulo, Brasil. São Paulo: Cetesb, 1994.

SANTOS, Milton. Espaço e método. São Paulo: Nobel, 1985.

Metamorfoses do espaço habitado. São Paulo: Hucitec, 1994.

SÃO PAULO (Estado). Instituto Geográfico e Geológico. Cartas da Região Sul do Brasil: Santos. São Paulo: IGGSP, 1971.

Secretaria do Meio Ambiente. Atlas das Unidades de Conservação Ambiental do Estado de São Paulo: Parte I: Litoral. São Paulo: SMA, 1996. 